\title{
The Trapezium in the great nebula of Orion. Great shower of falling stars.
}

I have read with much interest a translation of a letter, on the Trapezium of 0 rion, from $W$. Tempel which appeared in Number 1898 of the Astr. Nachr. 1 am desirous of making a few remarks on the visibility of the small stars in the interior of the Trapezium as there is some reason to suppose, from the evidence of experienced observers that they are variable. The $5^{\text {th }}$ and $6^{\text {th }}$ stars (in the order of brilliancy) were probably brighter at the earlier part of the present year than was formerly the case for several observers have succeeded in detecting them with telescopes of only about three inches aperture. M. Tempel also remarks that, in the spring, he could see them easily with a 4 inch refracting instrument and this statement corroborate the results obtained in this country. Altogether ten stars have been seen to constitute the Trapezium but I believe that this has only been accomplished on one occasion and that was by the late Mr. Edward Salter of Manchester who employed a 12 inch reflector of superior quality. Their positions were carefully noted by him and as it may be interesting to compare his sketch with the drawing of Liapounov's, I enclose a copy for insertion in the "Astronomische Nachrichten." The stars are numbered in the

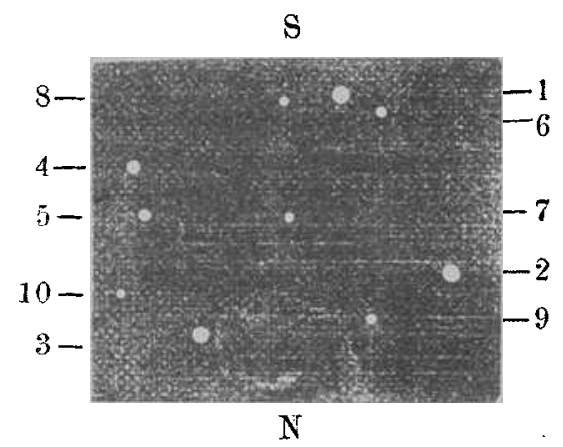

order of their brillianey. Mr. Salter remarked that the $10^{\text {th }}$ star was exceedingly faint and only visible by glimpses in moments of good definition. Several of the others were also extremely minute and only visible after very careful attention. In the sketch I enclose the stars are not quite accurately placed in their respective positions but it may be considered a good approximate representation of their appearance. It is very desirable that observers examine the Trapezium on all favorable occasions during the present winter months so that our knowledge of this exquisite object may be augmented. There is a strong suspicion that some of the small stars in the interior are very variable in the amount of light they emit and a series of observations would soon definately settle this interesting question.
A most remarkable and well sustained shower of falling stars was observed at many places in this country on the evening of November 27 last but it was not generally observed in consequence of the cloudy state of the sky as seen from some situations. At Bristol the weather was partially cloudy but between $5^{\mathrm{h}} 50^{\mathrm{m}}$ and $6^{\mathrm{h}} 30^{\mathrm{m}}$, mean time, I saw 79 meteors. During this time there were but very few of the brighter stars visible, a fact attributable to the existence of clouds and mist. All the shooting stars that I saw must therefore have been of the larger class, indeed I donot think I saw any less in apparent brightness than a $2^{\text {nd }}$ mag. star. The radiant point of the meteors was between Perseus and Andromeda and about 5 degrees to the north of the latter constellation. This is at Right Ascension $1^{\mathrm{h}} 56^{\mathrm{m}}$; north Declination 46 degrees. Some of the meteors were very bright but not equal to some which came under my observation during the progress of the great meteoric display of November $13-14,1866$. The number of falling stars seen during the recent shower of them must have been very considerable. Mr. E. J. Lowe of Nothingham counted 1237 in 20 minutes of observation and it was estimated by him that during the 4 hours and 40 minutes between $5^{h} 50^{\mathrm{m}}$ and $10^{\mathrm{h}} 30^{\mathrm{m}}$, mean time, there must been more than 58,000 visible in the whole sky. Professor A. J. Herschel also observed the falling stars from Newcastle and counted 453 in 35 minutes, observers agree in describing this shower as a most exceptionally grand one which has not been equalled since November 1866 . The meteurs seen on that occasion were larger as a body, than those which recently came under observation. Still the meteoric display to which I have referred was a very brilliant one and it is unfortunate that comparatively so few observers witnessed it. It does not seem altogether improbable that it was originated by the earth passing through the node of the periodical comet of Biela. This comet has not been seen of late years though it has several times returned to our parts of space. Is it, therefore, in process of dissipation and the source from whence the many meteors seen at this time of the year derive their origin? There is undoubtedly a connection excisting between meteoric showers and cometary orbits and it now remains for astronomers to endeavour to form, from the data that will be collected and discussed, a clearer conception as to the phenomena to which I have briefly directed attention.

William F. Denning.

Hollywood Lodge Cotham, Bristol, England, 1872 Dec. 2. 